This is an Accepted Manuscript of an article published by Taylor \& Francis in Journal of Environmental Science and Health, Part A on 18 Sept 2017, available online: http://

www.tandfonline.com/10.1080/10934529.2017.1357406 


\title{
Metronidazole removal in powder-activated carbon and concrete- containing graphene adsorption systems: Estimation of kinetic, equilibrium and thermodynamic parameters and optimization of adsorption by a central composite design
}

\author{
S. V. Manjunath ${ }^{\mathrm{a}}$, S. Mathava Kumar, ${ }^{\mathrm{a}, *}$, Huu Hao $\mathrm{Ngo}^{\mathrm{b}}$, and Wenshan Guo ${ }^{\mathrm{b}}$ \\ ${ }^{a}$ Department of Civil Engineering, Indian Institute of Technology Madras, Chennai, Tamil Nadu, India; \\ ${ }^{b}$ School of Civil and Environmental Engineering, University of Technology Sydney, Sydney, Australia \\ *Corresponding authors. Mathava Kumar (mathav@iitm.ac.in; mathavakumar@gmail.com); \\ Department of Civil Engineering, Indian Institute of Technology Madras, Chennai 600036, Tamil Nadu, \\ India.
}

\begin{abstract}
Metronidazole (MNZ) removal by two adsorbents, i.e., concrete-containing graphene (CG) and powder-activated carbon (PAC), was investigated via batch-mode experiments and the outcomes were used to analyze the kinetics, equilibrium and thermodynamics of $\mathrm{MNZ}$ adsorption. MNZ sorption on CG and PAC has followed the pseudo-second-order kinetic model, and the thermodynamic parameters revealed that MNZ adsorption was spontaneous on PAC and nonspontaneous on CG. Subsequently, two-parameter isotherm models, i.e., Langmuir, Freundlich, Temkin, Dubinin-Radushkevich and Elovich models, were applied to evaluate the MNZ adsorption capacity. The maximum MNZ adsorption capacities $\left(\mathrm{q}_{\mathrm{m}}\right)$ of PAC and CG were found to be between $25.5-32.8 \mathrm{mg} / \mathrm{g}$ and $0.41-0.002 \mathrm{mg} / \mathrm{g}$, respectively. Subsequently, the effects of $\mathrm{pH}$, temperature and adsorbent dosage on $\mathrm{MNZ}$ adsorption were evaluated by a central composite design (CCD) approach. The CCD experiments have pointed out the complete removal of MNZ at a much lower PAC dosage by increasing the system temperature (i.e., from $20^{\circ} \mathrm{C}$ to $40^{\circ} \mathrm{C}$ ). On the other hand, a desorption experiment has shown 3.5\% and 1.7\% MNZ removal from the surface of $\mathrm{PAC}$ and $\mathrm{CG}$, respectively, which was insignificant compared to the sorbed MNZ on the surface by adsorption. The overall findings indicate that PAC and CG with higher graphene content could be useful in MNZ removal from aqueous systems.
\end{abstract}

Keywords: Adsorption, isotherm, kinetics, metronidazole, thermodynamics

\section{Introduction}

Pharmaceuticals constitute a diverse group of organic compounds and are considered to be one of the most important emerging contaminants in the recent years. These include different compounds such as antibiotics, hormones, analgesics and anti-inflammatory drugs, antiepileptic drugs, blood lipid regulators, $\beta$ blockers, contrast media and cytostatic drugs. ${ }^{[1]}$ The usage of antibiotics has been increasing considerably day by day owing to the personal requirements of people, and demand in industries such as animal pharmaceuticals, aquaculture, poultries, piggeries, etc. The discharge of antibiotics into the environment could produce antimicrobial-resistant genes and they can also produce eco-toxicity. ${ }^{[2]}$ Antibiotics and/or their metabolites were found to have longer stability or half-life in aqueous and soil environments. Recent studies have reported the persistence of 
antibiotics of different classes in aqueous environments ${ }^{[3-5]}$ and the release of antibiotics from wastewater treatment plant effluents. ${ }^{[6,7]}$ Metronidazole (MNZ), an antibacterial and antiinflammatory agent, ${ }^{[8]}$ is one of the heavily used antibiotics worldwide, ${ }^{[9]}$ which has been used to treat diseases caused by anaerobic bacteria, bacteroides and protozoa. MNZ has very high solubility $(9.8 \mathrm{~g} / \mathrm{L})$ and molecular diffusivity $\left(8.48 \times 10^{6} \mathrm{~cm}^{2} / \mathrm{s}\right)$ in water, and is expected to be highly mobile in aqueous systems. Recently, Rosal et al. ${ }^{[10]}$ reported the presence of MNZ concentration in the influent $(165 \mathrm{ng} / \mathrm{L})$ and effluent $(127 \mathrm{ng} / \mathrm{L})$ samples of a sewage treatment plant.

The conventional wastewater treatment process relies mainly on the function of biological treatment units. However, these units are ineffective in the removal of a wide variety of antibiotics including MNZ. ${ }^{[11]}$ Therefore, it is vital to include appropriate technology (as a tertiary treatment) in the treatment process to remove the emerging contaminants including MNZ. Due to the increasing interest in the removal of antibiotics from aqueous systems, several researchers explored the possibility of MNZ removal by electrochemical process, ${ }^{[12]}$ photocatalysis, ${ }^{[13]}$ electro-catalytic reduction, ${ }^{[14]}$ membrane process,${ }^{[15]}$ Fenton process ${ }^{[16]}$ and coupled electro-reduction-biological treatment, ${ }^{[17]}$ etc. However, adsorption, one of the oldest techniques, has been found to be very effective in the removal of a wide variety of trace and gross organics. Moreover, this process has been used extensively in the wastewater treatment process owing to its ease in operation, low cost, absence of by-product formation, regeneration potential and sludge-free operation when compared to other treatment methods. ${ }^{[18,19]}$

Due to rapid and excessive urbanization, construction and demolition wastes have become a major concern in the context of urban solid waste management. ${ }^{[20]}$ The disposal of construction and demolition wastes has become one of the biggest concerns throughout the world, as it is generated in huge quantities. Landfilling of construction and demolition wastes is the main current practice in many developing countries. Moreover, it was reported that the wastes were dumped illegally on land or in natural drainages in most developing countries due to shortage of space for dumping. However, the construction and demolition wastes containing cementitious material can be reused or recycled for other processes/applications. Several investigations in the past reported the application of cementitious materials in the removal of various pollutants from water and wastewater including phosphorous by composite cement mortars; ${ }^{[21]}$ fecal coliforms and phosphorous by pervious geopolymer concrete; ${ }^{[22]} \mathrm{p}$-chloronitrobenzene by the cementitious catalytic membrane with ozonation; ${ }^{[23]}$ Indigo carmine by concrete composite; ${ }^{[24]}$ and heavy metals $(\mathrm{Cu}, \mathrm{Cd}, \mathrm{Zn}$ and $\mathrm{Pb})$ by zeolite-Portland cement mixture. ${ }^{[25]}$

In the recent years, graphene and graphene composites have been used as adsorbents to treat water and wastewater containing heavy metals, organic dyes and antibiotics. To mention a few, ironaluminum oxide-graphene oxide composite for fluoride removal, ${ }^{[26]}$ graphene oxide for removing diclofenac and sulfamethoxazole antibiotics, ${ }^{[27]}$ polysaccharide-modified graphene oxides for the removal of cationic dyes (Methylene blue, Rhodamine 6G) and anionic dyes (Orange II, Acid fuchsin), ${ }^{[28]}$ and graphene oxide membranes for $\mathrm{Cu}^{2+}, \mathrm{Cd}^{2+}$ and $\mathrm{Ni}^{2+}$ removal are some examples. ${ }^{[29]}$ On the other hand, several investigations are in progress to study the addition of graphene/graphene oxide in the concrete preparation to increase its strength and other characteristics. The application of concrete prepared with the addition of graphene for water purification especially for antibiotics' removal has not been investigated. Moreover, the requirement/suitability of graphene content in 
concrete for the effective removal of antibiotics was not addressed in the past. At the same time, it is essential to compare the performance of modified concrete with graphene with commercially available adsorbents including PAC which has huge importance in the application of modified concrete for water purification applications. On the other hand, the interaction effect of adsorbent dosage, $\mathrm{pH}$ and temperature on the removal of antibiotics using a central composite design (CCD) along with isotherm experiments was not carried out in the past. Therefore, this investigation was focused to evaluate the performance of concrete-containing graphene (CG) in MNZ removal and its effectiveness was compared with the MNZ removal potential of powdered activated carbon (PAC) by calculating the kinetic rates, thermodynamic parameters and adsorption capacity using isotherms. Moreover, this study was extended to explore (a) the interaction effects of temperature, $\mathrm{pH}$ and adsorbent dosage on MNZ removal and (b) the extent of MNZ desorption from CG and PAC.

\section{Materials and methods}

\subsection{Preparation of adsorbent}

PAC was supplied by Merck, India, and it was used without any modification. CG (2\%w/w, 1$2 \mathrm{~mm}$ size) was obtained from the Building Technology and Construction Management laboratory of IIT Madras, India. Prior to the adsorption experiments, the CG specimen was crushed, and the particles retained between ASTM sieve Nos. 8 and 16 were collected and washed several times with tap water followed by distilled water. Subsequently, the particles were air-dried and stored in an airtight container for further use. The surface morphology of the adsorbents before and after adsorption was analyzed by using a scanning electron microscope (GENESIS-2100 SEM, EmCrafts, South Korea).

\subsection{Preparation of adsorbate}

MNZ $\left(\mathrm{C}_{6} \mathrm{H}_{9} \mathrm{~N}_{3} \mathrm{O}_{3}\right)$ of analytical grade supplied by Sigma-Aldrich was used for the preparation of stock solution $(1,000 \mathrm{mg} / \mathrm{L})$. The prepared stock solution was placed in a volumetric flask, sealed and stored in a refrigerator. The working solutions of required concentrations were prepared from the stock solution $(1,000 \mathrm{mg} / \mathrm{L})$ by diluting it with distilled water.

\subsection{Kinetic and equilibrium adsorption study}

\subsubsection{Kinetic study}

The kinetic study was conducted in a batch mode at an initial MNZ concentration of $10 \mathrm{mg} / \mathrm{L}$. Exactly $100 \mathrm{~mL}$ of solution containing $10 \mathrm{mg} / \mathrm{L} \mathrm{MNZ} \mathrm{was} \mathrm{poured} \mathrm{into} 250-\mathrm{mL}$ conical flasks, and the adsorbent (either PAC or CG) was added into the flasks at a predetermined adsorbate-toadsorbent ratio (basis of wt:wt; 1:100 for PAC and 1:1,000 for CG). Subsequently, the flasks were kept in a temperature-controlled incubator shaker at $25^{\circ} \mathrm{C}$ with continuous shaking at $100 \mathrm{rpm}$ for $24 \mathrm{~h}$. At regular time intervals, the samples were withdrawn from the flasks and analyzed for MNZ concentration.

\subsubsection{Equilibrium study}


Batch-mode equilibrium adsorption experiments were conducted under similar operating conditions, i.e., at $25^{\circ} \mathrm{C}, 100-\mathrm{mL}$ working volume with continuous shaking with a range of initial MNZ concentrations $(5,10,25,50$ and $100 \mathrm{mg} / \mathrm{L})$. The adsorbate-to-adsorbent ratio was fixed as 1:100 and 1:1,000 (on a wt:wt basis) for PAC and CG, respectively. The experiments were conducted for a pseudo-equilibrium time obtained from the kinetic study. At the end of the experiment, the samples were collected from the flasks and analyzed for MNZ concentration. Using the experimental data, $\mathrm{MNZ}$ adsorption capacity $\mathrm{q}_{\mathrm{e}}(\mathrm{mg} / \mathrm{g})$ at equilibrium was calculated as given in Eq. (1):

$$
q_{e}=\frac{\left(C_{o}-C_{e}\right) V}{M}
$$

where $\mathrm{C}_{0}$ and $\mathrm{C}_{\mathrm{e}}$ are $\mathrm{MNZ}$ concentrations at the start of the experiment and at equilibrium $(\mathrm{mg} / \mathrm{L})$, respectively. $\mathrm{V}$ is the volume of $\mathrm{MNZ}$ solution (L) and $\mathrm{M}$ is the mass of adsorbent $(\mathrm{g})$.

\subsection{Quantification of MNZ concentration}

After the adsorption study, an aliquot of MNZ solution was collected, centrifuged and filtered. Subsequently, the filtered sample was analyzed using high-performance liquid chromatography (HPLC) fitted with a UV-Vis variable wavelength detector (Dionex UltiMate 3000). The C18 chromatographic column (Acclaim 120,5 $\mathrm{m}, 4.6 \times 250 \mathrm{~mm}$ ) was used to separate the compounds. The column was operated at a reverse phase mode at a wavelength of $254 \mathrm{~nm}$ using acetonitrile:water (60:40) as a mobile phase. The pump was operated at a flow rate of $1 \mathrm{~mL} / \mathrm{min}$. The HPLC analysis results were used to calculate the MNZ removal as per Eq. (2):

$$
M N Z \text { removal }(\%)=\left(\frac{C_{o}-C_{e}}{C_{o}}\right) * 100
$$

\subsection{Determination of rate constants}

The rate of adsorption was determined using the adsorption equilibrium data and equilibrium models (i.e., the pseudo-first-order and pseudo-second-order models).

Pseudo-first-order model

Lagergren's pseudo-first-order rate equation [Eq. (3)] describes the adsorption of liquid-solid systems based on the concentration of the solution and adsorption capacity of the solid. Equation (3) states that the rate of adsorption is equal to the distance to equilibrium. At time $t=0$ for fresh adsorbent, $\mathrm{q}_{\mathrm{t}}=0$ and the distance of equilibrium is $\mathrm{q}_{\mathrm{e}}$. The increase in time reduces the distance of equilibrium, while the distance disappears at equilibrium, i.e., $\mathrm{q}_{\mathrm{e}}-\mathrm{q}_{\mathrm{t}}=0 .{ }^{[30]}$ Equation (4) depicts the expression for the pseudo-first-order model in a linearized form:

$$
\begin{gathered}
\frac{d q}{d t}=K_{1}\left(q_{e}-q_{t}\right) \\
\ln \left(q_{e}-q_{t}\right)=\ln q_{e}-K_{1} t
\end{gathered}
$$

where $\mathrm{q}_{\mathrm{e}}$ and $\mathrm{q}_{\mathrm{t}}$ are adsorption capacities $(\mathrm{mg} / \mathrm{g})$ at equilibrium and at various times $(\mathrm{t})$, respectively. $\mathrm{K} 1$ is the pseudo-first-order rate constant $\left(\mathrm{min}^{-1}\right)$ that was obtained by plotting a graph of $\ln \left(\mathrm{q}_{\mathrm{e}}-\mathrm{q}_{\mathrm{t}}\right)$ versus $t$. 
Pseudo-second-order model

The rate of pseudo-second-order reaction depends on the amount of adsorbate adsorbed on the adsorbent. The adsorption capacity at equilibrium is a function of temperature, adsorbent dosage, initial adsorbent concentration in solution and the nature of solute sorbent interaction. ${ }^{[31]}$ The pseudo-second-order model is based on the assumption that the rate-limiting step is chemisorption involving valency forces through sharing or exchange of electrons between the adsorbent and the adsorbate. ${ }^{[32]}$ The expressions for the pseudo-second-order model and the linearized form are given in Eqs. (5) and (6), respectively:

$$
\begin{aligned}
& \frac{d q}{d t}=K_{2}\left(q_{e}-q_{t}\right)^{2} \\
& \frac{t}{q_{t}}=\frac{1}{K_{2} q_{e}^{2}}+\frac{t}{q_{e}}
\end{aligned}
$$

where $\mathrm{K}_{2}$ is the pseudo-second-order rate constant $(\mathrm{g} / \mathrm{mg} / \mathrm{min})$ and it was obtained by plotting a graph $\left(\mathrm{t} / \mathrm{q}_{\mathrm{t}}\right)$ versus $\mathrm{t}$..

\subsection{Adsorption isotherm}

An adsorption isotherm represents the relationship between the amount of adsorbate adsorbed onto the surface of an adsorbent and the concentration of adsorbate in the solution at a constant temperature under the equilibrium condition. ${ }^{[33]}$ In this study, Langmuir, Freundlich, Temkin, Dubinin-Radushkevich and Elovich isotherm models were used to fit the experimental data.

Langmuir isotherm

The Langmuir isotherm model assumes that the adsorption is monolayer and takes place at specific homogeneous sites on the adsorbent. Once a pollutant occupies a site, no further adsorption can occur in that particular site, i.e., adsorbent has a finite capacity for the pollutant. There is no interaction between the molecules adsorbed onto the neighboring sites. ${ }^{[34]}$ The Langmuir isotherm is shown in Eq. (7):

$$
q_{e}=\frac{q_{m} K_{L} C_{e}}{1+K_{L} C_{e}}
$$

Where $\mathrm{q}_{\mathrm{e}}$ is the equilibrium adsorption capacity $(\mathrm{mg} / \mathrm{g}), \mathrm{q}_{\mathrm{m}}$ is the Langmuir isotherm constant representing monolayer adsorption capacity $(\mathrm{mg} / \mathrm{g}), \mathrm{C}_{\mathrm{e}}$ is the equilibrium concentration of $\mathrm{MNZ}$ in the solution $(\mathrm{mg} / \mathrm{L})$ and $\mathrm{K}_{\mathrm{L}}$ is the Langmuir constant. Equation (8) shows the linearized form of Langmuir isotherm:

$$
\frac{1}{q_{e}}=\frac{1}{q_{m}}+\frac{1}{q_{m} K_{L} C_{e}}
$$

The Langmuir isotherm constants, i.e., $\mathrm{K}_{\mathrm{L}}$ and $\mathrm{q}_{\mathrm{m}}$, are obtained by plotting a graph of $\frac{1}{q_{c}} \mathrm{vs} \frac{1}{C_{e}}$. Favorability of adsorption process is evaluated by a dimensionless parameter, i.e., separation or equilibrium parameter $R_{L}$, as shown in Eq. (9):

$$
R_{L}=\frac{1}{1+\left(K_{L} C_{0}\right)}
$$


If $\mathrm{R}_{\mathrm{L}}$ is $0<\mathrm{R}_{\mathrm{L}}<1$, the adsorption process is favorable, $\mathrm{R}_{\mathrm{L}}>1$ indicates that adsorption is unfavorable, $\mathrm{R}_{\mathrm{L}}=1$ indicates linear adsorption and $\mathrm{R}_{\mathrm{L}}=0$ indicates that the adsorption process is irreversible in nature.

Freundlich isotherm

The Freundlich isotherm [Eq. (10)] is an empirical expression based on the assumption that the adsorbent has a heterogeneous surface composed of different classes of adsorption sites. This can be applied to multilayer adsorption, with a non-uniform distribution of adsorption heat and affinities over the heterogeneous surface. ${ }^{[35]}$

$$
q_{e}=K_{F} C_{e}^{\frac{1}{n}}
$$

Where $\mathrm{K}_{\mathrm{F}}$ is the Freundlich isotherm constant signifying adsorption capacity and $\frac{1}{n}$ is the Freundlich constant representing intensity of the adsorption or surface heterogeneity, revealing higher heterogeneity as it tends to 0 . The value of Freundlich constant between 0 and 1 indicates favorable adsorption. Equation (11) shows the linearized form of Freundlich isotherm, and a plot of $\ln \left(\mathrm{q}_{\mathrm{e}}\right)$ versus $\ln \left(\mathrm{C}_{\mathrm{e}}\right)$ gives slope $\frac{1}{n}$ and intercept $\mathrm{K}_{\mathrm{F}}$.

$$
\ln q_{e}=\ln K_{F}+1 / n \ln C_{e}
$$

Temkin isotherm

The Temkin isotherm is based on the assumption that the heat of adsorption of all the molecules in a layer decreases linearly with a coverage due to adsorbent-adsorbate interactions. It mainly describes the chemical adsorption process as the one involving electrostatic interaction. ${ }^{[36]}$ Equations (12) and (13) represent the Temkin isotherm model and its linearized form, respectively:

$$
\begin{gathered}
q_{e}=B \ln \left(A_{T} C_{e}\right) \\
q_{e}=B \ln A_{T}+B \ln C_{e}
\end{gathered}
$$

Where $B$ is a constant related to heat of adsorption given by $B=\frac{R T}{\Delta Q}$ and $A_{T}$ is the Temkin equilibrium-binding constant $(\mathrm{L} / \mathrm{mol})$. A plot of qe versus $\ln \left(\mathrm{C}_{\mathrm{e}}\right)$ is used to estimate the slope $\mathrm{B}$ and intercept $\mathrm{A}_{\mathrm{T}}$.

Dubinin-Radushkevich isotherm

The Dubinin-Radushkevich isotherm model does not assume a homogeneous surface or a constant adsorption potential like the Langmuir model. ${ }^{[37]}$ Equations (14) and (15) represent the DubininRadushkevich isotherm model and its linearized form, respectively. Slope and intercept of the plot $\ln \left(\mathrm{q}_{\mathrm{e}}\right)$ vs $\varepsilon^{2}$ give $\mathrm{K}_{\mathrm{DR}}$ constant related to the mean free energy of adsorption $\left(\mathrm{mol}^{2} / \mathrm{kJ}^{2}\right)$ and maximum adsorption capacity $\left(\mathrm{q}_{\mathrm{m}}\right)$, respectively, where $\varepsilon$ indicates the Polanyi potential given by Eq. (16). The mean free energy value $(\mathrm{E})(\mathrm{kJ} / \mathrm{mol})$ can be found by using $\mathrm{K}_{\mathrm{DR}}$ values using Eq. (17). Any value of $\mathrm{E}$ less than $8 \mathrm{~kJ} / \mathrm{mol}$ indicates that the adsorption is physical in nature, whereas the $\mathrm{E}$ value between 8 and $16 \mathrm{~kJ} / \mathrm{mol}$ and greater than $16 \mathrm{~kJ} / \mathrm{mol}$ indicates the adsorption by exchange of ions and chemisorption, respectively. ${ }^{[38]}$ 


$$
\begin{gathered}
q_{e}=q_{m} \exp \left(-K_{D R} \varepsilon^{2}\right) \\
\ln q_{e}=\ln \left(q_{m}\right)-\left(K_{D R} \varepsilon^{2}\right) \\
\varepsilon=R \ln \left[1+\frac{1}{C_{e}}\right] \\
E=\left[\frac{1}{\sqrt{2 K_{D R}}}\right]
\end{gathered}
$$

Elovich isotherm

The Elovich isotherm model is based on the assumption that adsorption sites increase exponentially with adsorption, which implies a multilayer adsorption. ${ }^{[39]}$ Equations (18) and (19) represent the Elovich isotherm model and its linearized form, respectively. The slope and intercept of the plot $\ln \left(\mathrm{q}_{\mathrm{e}} / \mathrm{C}_{\mathrm{e}}\right)$ versus $\mathrm{q}_{\mathrm{e}}$ give maximum adsorption capacity $\left(\mathrm{q}_{\mathrm{m}}\right)$ and Elovich equilibrium constant $\left(\mathrm{K}_{\mathrm{E}}\right.$ in $\mathrm{L} / \mathrm{mg}$ ), respectively:

$$
\begin{aligned}
& \frac{q_{e}}{q_{m}}=K_{E} C_{e} \exp \left[-\frac{q_{e}}{q_{m}}\right] \\
& \ln \frac{q_{e}}{C_{e}}=\ln K_{E} q_{m}-\frac{1}{q_{m}} q_{e}
\end{aligned}
$$

\subsection{Estimation of thermodynamic parameters}

Adsorption thermodynamics play a vital role in understanding adsorption mechanisms, i.e., physisorption or chemisorption. Thermodynamic parameters such as change in free energy $\left.\Delta \mathrm{G}^{0}\right)$, enthalpy $\left(\Delta \mathrm{H}^{0}\right)$ and entropy $\left(\Delta \mathrm{S}^{0}\right)$ were used to determine the spontaneity, heat of change and randomness in the adsorption of MNZ using Eqs. (20)-(22), respectively:

$$
\Delta G^{o}=-R T \ln k_{c}
$$

$\Delta \mathrm{G}^{0}$ is related to the change in enthalpy and entropy given by Eq. (21):

$$
\Delta G^{o}=\Delta H^{o}-T \Delta S^{o}
$$

The entropy value can be obtained by combining Eqs. (20) and (21) as shown in Eq. (22):

$$
\ln k_{c}=-\frac{\Delta H^{o}}{R T}+\frac{\Delta S^{o}}{R}
$$

Where $\Delta \mathrm{G}^{0}$ is Gibbs free energy change $(\mathrm{J} / \mathrm{mol}), \Delta \mathrm{H}^{0}$ is the change in enthalpy $(\mathrm{J} / \mathrm{mol}), \Delta \mathrm{S}^{0}$ is the change in entropy $(\mathrm{J} / \mathrm{mol} / \mathrm{K}), \mathrm{R}$ is a universal gas constant $(8.314 \mathrm{~J} / \mathrm{mol} \mathrm{K}), T$ is the absolute temperature $(\mathrm{K})$ and $\mathrm{k}_{\mathrm{c}}$ is the equilibrium constant. ${ }^{[40]}$ The value of $\mathrm{k}_{\mathrm{c}}$ can be calculated using Eq. (23):

$$
k_{c}=\frac{q_{e}}{C_{e}}
$$

The slope and intercept of the plot $\ln \left(\mathrm{k}_{\mathrm{c}}\right)$ versus $(1 / \mathrm{T})$ give $\Delta \mathrm{H}^{0}$ and $\Delta \mathrm{S}^{0}$, respectively. To determine the thermodynamics' parameters, batch adsorption studies were carried out at $10 \mathrm{mg} / \mathrm{L} \mathrm{MNZ}$ concentration, at pH 7 and under three different temperatures (i.e., 293, 303 and $313 \mathrm{~K}$ ). 


\subsection{Optimization of adsorption conditions by a central composite design}

The effects of $\mathrm{pH}\left(\mathrm{x}_{1}\right)$, temperature ( $\left.\mathrm{x}_{2}\right)$ and adsorbent dosage ( $\mathrm{x}_{3}$; either CG or PAC), i.e., effect of independent variables, on MNZ adsorption were evaluated by using a $\mathrm{CCD}$. The ranges selected for the independent variables are as follows: $\mathrm{x}_{1} \sim 3-11, \mathrm{x}_{2} \sim 20-40^{\circ} \mathrm{C}$ and $\mathrm{x}_{3} \sim 10-1,000 \mathrm{mg} / \mathrm{L}$. A three-factor full factorial CCD was constructed using Minitab 16 and the design is shown in Table 1. The effect of independent variables on MNZ adsorption was evaluated by calculating MNZ removal ( $\mathrm{Y}_{1}$; in \%) and Gibbs free energy of adsorption $\mathrm{Y}_{2}$; in $\mathrm{J} / \mathrm{mol}$ ). Using the experimental design, the experiments (Runs 1-20) were conducted in a batch mode with continuous shaking at an initial $\mathrm{MNZ}$ concentration of $10 \mathrm{mg} / \mathrm{L}$ for predetermined equilibrium time. At the end of the experiment, samples were collected and analyzed for MNZ concentration using HPLC. The center point was repeated six times to ensure the reproducibility of the experimental outcomes.

Table 1. The conditions of CФD experiments and the outcomes.

\begin{tabular}{|c|c|c|c|c|c|c|c|c|c|}
\hline \multirow[b]{3}{*}{ Run No. } & \multirow[b]{3}{*}{$\mathrm{pH}$} & \multirow[b]{3}{*}{ Temp $\left({ }^{\circ} \mathrm{C}\right)$} & \multirow[b]{3}{*}{ Adsorbent dosage (mg/L) } & \multicolumn{4}{|c|}{ MNZ removal $\left(Y_{1}, \%\right)$} & & \\
\hline & & & & \multicolumn{2}{|c|}{ PAC system } & \multicolumn{2}{|c|}{ CG system } & \multicolumn{2}{|c|}{$\Delta G^{o}\left(\mathrm{Y}_{2}, \mathrm{~J} / \mathrm{mol}\right)$} \\
\hline & & & & Exp & Pre & Exp & Pre & PAC system & CG system \\
\hline 1 & 7 & 30 & 505 & 93.00 & 92.75 & 22.33 & 23.86 & $-4,181.8$ & $5,473.8$ \\
\hline 2 & 11 & 30 & 505 & 89.94 & 101.69 & 22.45 & 24.86 & $-3,184.5$ & $5,455.4$ \\
\hline 3 & 3 & 30 & 505 & 98.65 & 105.50 & 23.38 & 25.68 & $-8,484.9$ & $5,323.9$ \\
\hline 4 & 7 & 30 & 9 & 13.49 & 47.45 & 6.65 & 12.21 & $-3,130.3$ & $-1,159.2$ \\
\hline 5 & 7 & 30 & 505 & 93.03 & 92.75 & 22.98 & 23.86 & $-4,194.3$ & $5,380.7$ \\
\hline 6 & 7 & 30 & 1001 & 99.42 & 83.91 & 23.90 & 23.06 & $-8,901.8$ & $6,975.2$ \\
\hline 7 & 7 & 30 & 505 & 93.07 & 92.75 & 23.27 & 23.86 & $-4,211.1$ & $5,339.4$ \\
\hline 8 & 7 & 30 & 505 & 93.65 & 92.75 & 23.58 & 23.86 & $-4,444.7$ & $5,295.1$ \\
\hline 9 & 9.4 & 36 & 210 & 96.51 & 79.51 & 21.88 & 19.94 & $-8,406.8$ & $3,395.2$ \\
\hline 10 & 4.6 & 36 & 210 & 97.47 & 82.37 & 23.59 & 21.11 & $-9,251.8$ & $3,145.4$ \\
\hline 11 & 7 & 20 & 505 & 91.21 & 102.72 & 21.89 & 24.69 & $-3,441.6$ & $5,355.8$ \\
\hline 12 & 7 & 30 & 505 & 93.38 & 92.75 & 23.28 & 23.86 & $-4,332.7$ & $5,337.2$ \\
\hline 13 & 4.6 & 24 & 210 & 97.62 & 80.82 & 22.52 & 19.58 & $-9,053.9$ & $3,172.0$ \\
\hline 15 & 9.4 & 36 & 800 & 99.20 & 102.54 & 25.27 & 28.20 & $-8,818.2$ & $6,346.8$ \\
\hline 16 & 4.6 & 24 & 800 & 97.62 & 101.15 & 22.98 & 24.22 & $-5,751.3$ & $6,409.8$ \\
\hline 17 & 7 & 30 & 505 & 94.06 & 92.75 & 23.01 & 23.86 & $-4,623.8$ & $5,375.4$ \\
\hline 18 & 9.4 & 24 & 800 & 97.84 & 99.48 & 21.94 & 24.42 & $-5,991.8$ & $6,557.5$ \\
\hline 19 & 9.4 & 24 & 210 & 97.84 & 78.83 & 21.65 & 19.43 & $-9,294.5$ & $3,296.6$ \\
\hline 20 & 7 & 40 & 505 & 99.50 & 106.59 & 27.24 & 29.16 & $-11,341.2$ & $4,967.3$ \\
\hline
\end{tabular}

Note: Exp—experimental values and Pre—predicted values based on the quadratic model obtained from CCD.

\subsection{Desorption study}

MNZ desorption from the adsorbents was evaluated using the adsorbents recovered (after carefully decanting the supernatant) at the end of the experiments from the equilibrium study. The flasks containing the adsorbents recovered from various systems (i.e., initial MNZ concentrations of 1, 5, 10,50 and $100 \mathrm{mg} / \mathrm{L}$ ) were added with $100-\mathrm{mL}$ distilled water and kept in a temperature-controlled incubator shaker at $25^{\circ} \mathrm{C}$ for $24 \mathrm{~h}$. The supernatant was withdrawn from flasks at the end of $24 \mathrm{~h}$ and analyzed for MNZ concentration. The difference in MNZ concentration, i.e., MNZ adsorbed in the adsorbents and in the supernatant after $24 \mathrm{~h}$, was considered as an irreversible portion of MNZ from the adsorbent due to chemisorption.

\section{Results and discussion}

\subsection{Effect of contact time and kinetics of MNZ adsorption}


The effects of contact time on MNZ concentration and MNZ adsorption capacity in the presence of PAC and CG as adsorbents are shown in Figure 1a and b, respectively. It could be noticed in Figure 1 that MNZ adsorption on PAC was four times higher than CG at the end of 5 min of adsorption. In the PAC system, the calculated qe was found to be $9.88 \mathrm{mg} / \mathrm{g}$ at the end of $5 \mathrm{~min}$ and no significant change was observed thereafter. The $\mathrm{q}_{\mathrm{e}}$ profile in the CG system was similar to that of the PAC system; however, the value was nearly 45 times less compared to that of the PAC system. This could be due to the availability of large number of adsorption sites in PAC compared to $\mathrm{CG}$.

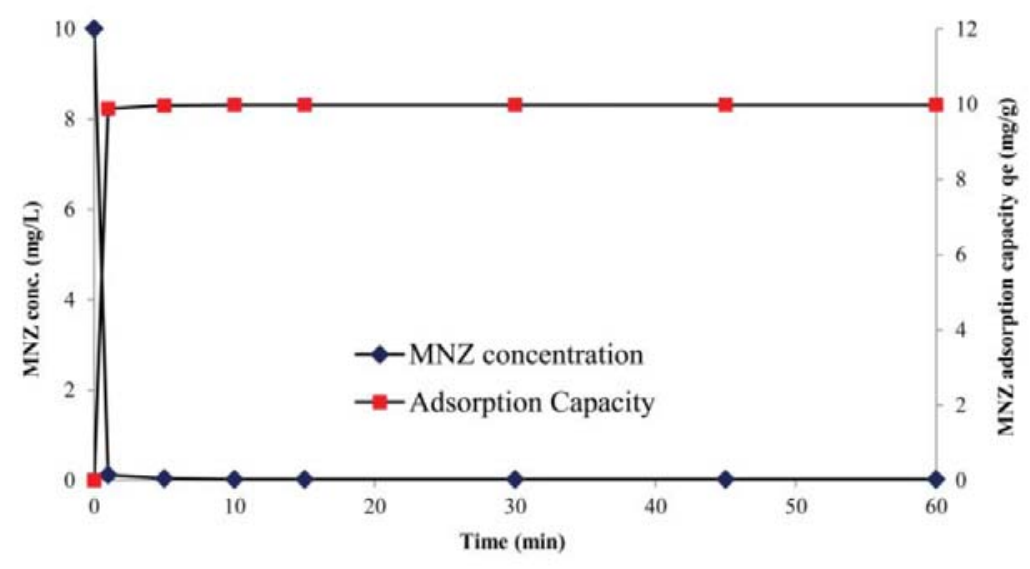

(a)

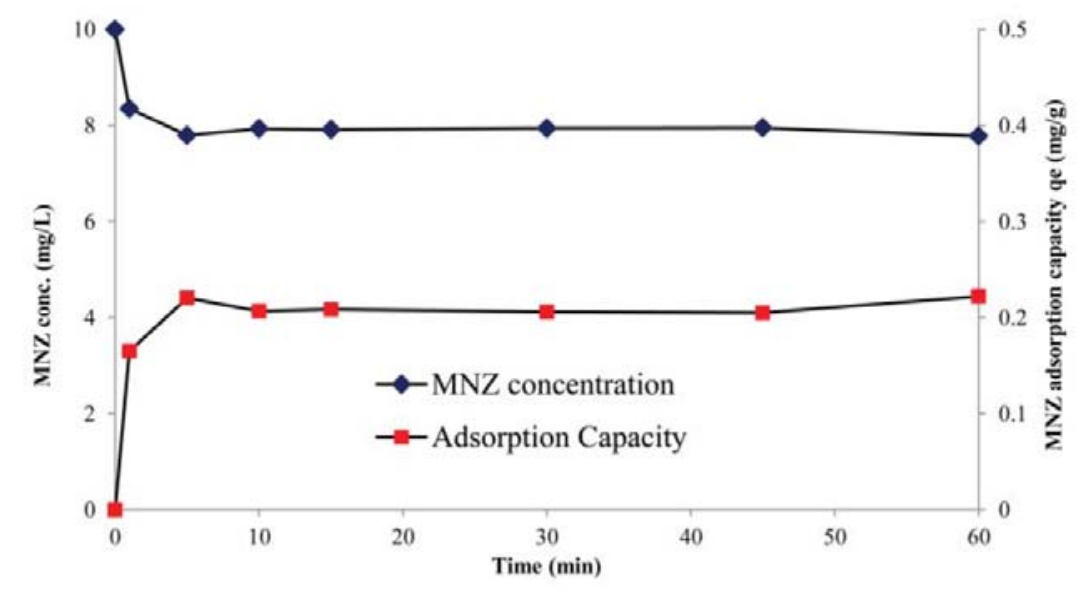

(b)

Figure 1. Effect of contact time on initial MNZ concentration on adsorption capacity (a) PAC (b) CG.

The order of reaction and reaction rate constant were found using Eqs. (3)-(6). The linearized plots of pseudo-first-order and pseudo-second-order models for both PAC and CG were prepared (Supporting information, Figures $2 \mathrm{~S}$ and $3 \mathrm{~S}$ ); the rate constants were calculated and they are reported in Table 2. From the plots and Table 2, it was observed that the pseudo-second-order model was found to fit well the data of kinetic study. This shows that MNZ adsorption on both PAC and CG follows the second-order kinetics $\left(\mathrm{R}^{2}\right.$ of 1.00 and 0.997 for PAC and CG, respectively). On the other hand, the coefficient of determination for the pseudo-first-order model 
was found to be very less for both PAC (0.368) and CG (0.264) adsorption systems. However, the values of the pseudo-second-order-kinetic constant $\left(\mathrm{K}_{2}\right)$ were found to be 16.73 and $7.98 \mathrm{~g} / \mathrm{mg} / \mathrm{min}$ for PAC and CG, respectively, which reveals that MNZ removal is rapid and spontaneous on PAC compared to $\mathrm{CG}$. The calculated $\mathrm{q}_{\mathrm{e}}\left(\mathrm{q}_{\mathrm{e}-\mathrm{calc}}\right)$ values from the pseudo-second-order models (Supporting information; Table 1S) agreed well with the experimental $\mathrm{q}_{\mathrm{e}}\left(\mathrm{q}_{\mathrm{e}-\mathrm{exp}}\right)$ values of PAC and CG adsorption systems (Table 2). The goodness of fit of the pseudo-second-order model confirms that the kinetic sorption of MNZ on both PAC and CG is mainly due to chemisorption.

Table 2. Calculated values of kinetic and isotherm constants.

\begin{tabular}{|c|c|c|c|c|c|c|}
\hline Model type & Model name & Parameters & PAC & $\mathrm{R}^{2}$ & CG & $\mathrm{R}^{2}$ \\
\hline \multirow[t]{6}{*}{ Kinetic model } & \multirow[t]{3}{*}{ Pseudo-first-order } & $q_{e-\exp }(\mathrm{mg} / \mathrm{g})$ & 9.99 & \multirow[t]{3}{*}{0.368} & 0.22 & \multirow[t]{3}{*}{0.264} \\
\hline & & $q_{c-\text { calc }}(\mathrm{mg} / \mathrm{g})$ & 0.030 & & 0.026 & \\
\hline & & $K_{1}\left(\min ^{-1}\right)$ & 0.025 & & 0.019 & \\
\hline & \multirow[t]{3}{*}{ Pseudo-second-order } & $q_{e-\exp }(\mathrm{mg} / \mathrm{g})$ & 9.99 & \multirow[t]{3}{*}{1.00} & 0.22 & \multirow[t]{3}{*}{0.997} \\
\hline & & $q_{e-\text { calc }}(\mathrm{mg} / \mathrm{g})$ & 9.98 & & 0.21 & \\
\hline & & $K_{2}(\mathrm{~g} / \mathrm{mg} / \mathrm{min})$ & 16.73 & & 7.98 & \\
\hline \multirow[t]{11}{*}{ Isotherm model } & \multirow[t]{2}{*}{ Langmuir } & $q_{m}(\mathrm{mg} / \mathrm{g})$ & 54.35 & \multirow[t]{2}{*}{0.991} & 0.076 & \multirow[t]{2}{*}{0.659} \\
\hline & & $K_{L}(\mathrm{~L} / \mathrm{mg})$ & 3.29 & & 0.146 & \\
\hline & \multirow[t]{2}{*}{ Freundlich } & $K_{F}$ & 32.78 & \multirow[t]{2}{*}{0.953} & 0.002 & \multirow[t]{2}{*}{0.925} \\
\hline & & $1 / n$ & 0.4655 & & 1.082 & \\
\hline & \multirow[t]{2}{*}{ Temkin } & $A_{T}(\mathrm{~L} / \mathrm{mg})$ & 30.60 & \multirow[t]{2}{*}{0.977} & 0.1416 & \multirow[t]{2}{*}{0.806} \\
\hline & & $B(\mathrm{~J} / \mathrm{mol})$ & 13.646 & & 3.123 & \\
\hline & \multirow[t]{3}{*}{ Dubinin- Radushkevich } & $q_{m}(\mathrm{mg} / \mathrm{g})$ & 55.13 & \multirow[t]{3}{*}{0.919} & 0.41 & \multirow[t]{3}{*}{0.835} \\
\hline & & $K_{D R}\left(\mathrm{~mol}^{2} / \mathrm{kJ}^{2}\right)$ & $3.00 \mathrm{E}-8$ & & $2.00 \mathrm{E}-5$ & \\
\hline & & $E(\mathrm{~kJ} / \mathrm{mol})$ & $4,082.48$ & & 223.60 & \\
\hline & \multirow[t]{2}{*}{ Elovich } & $q_{m}(\mathrm{mg} / \mathrm{g})$ & 25.45 & \multirow[t]{2}{*}{0.994} & 9.643 & \multirow[t]{2}{*}{0.396} \\
\hline & & $K_{E}(\mathrm{~L} / \mathrm{mg})$ & 9.137 & & 1.740 & \\
\hline
\end{tabular}

Note: $q_{e-\exp }$ is the experimental equilibrium adsorption cacity and $q_{e-c a l c}$ is the calculated equilibrium adsorption capacity.

\subsection{Equilibrium study}

\subsubsection{Effect of initial MNZ concentration}

The effect of initial MNZ concentration on percentage removal and equilibrium adsorption capacity of PAC and CG in MNZ removal is shown in Figure 2a and b, respectively. It can be observed that the adsorption capacity of MNZ increased when the initial MNZ concentration also increased. This may be attributed to a higher probability of collision between the adsorbent and the adsorbate, which might have provided force to overcome the resistance of mass transfer of MNZ between aqueous and solid phases. ${ }^{[41]}$ The MNZ removal percentage in the PAC system decreased from $99 \%$ to $87 \%$ when the initial concentration increased from $5 \mathrm{mg} / \mathrm{L}$ to $100 \mathrm{mg} / \mathrm{L}$. The decrease in MNZ removal could be attributed to the saturation of adsorption sites above a certain MNZ concentration. ${ }^{[42]}$

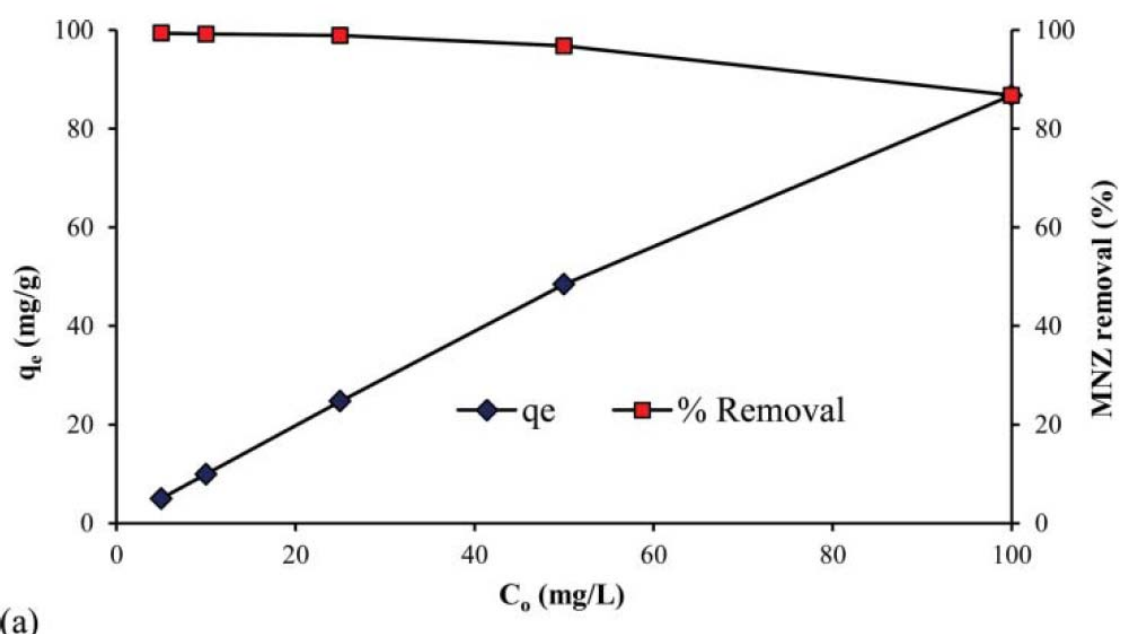

(a) 


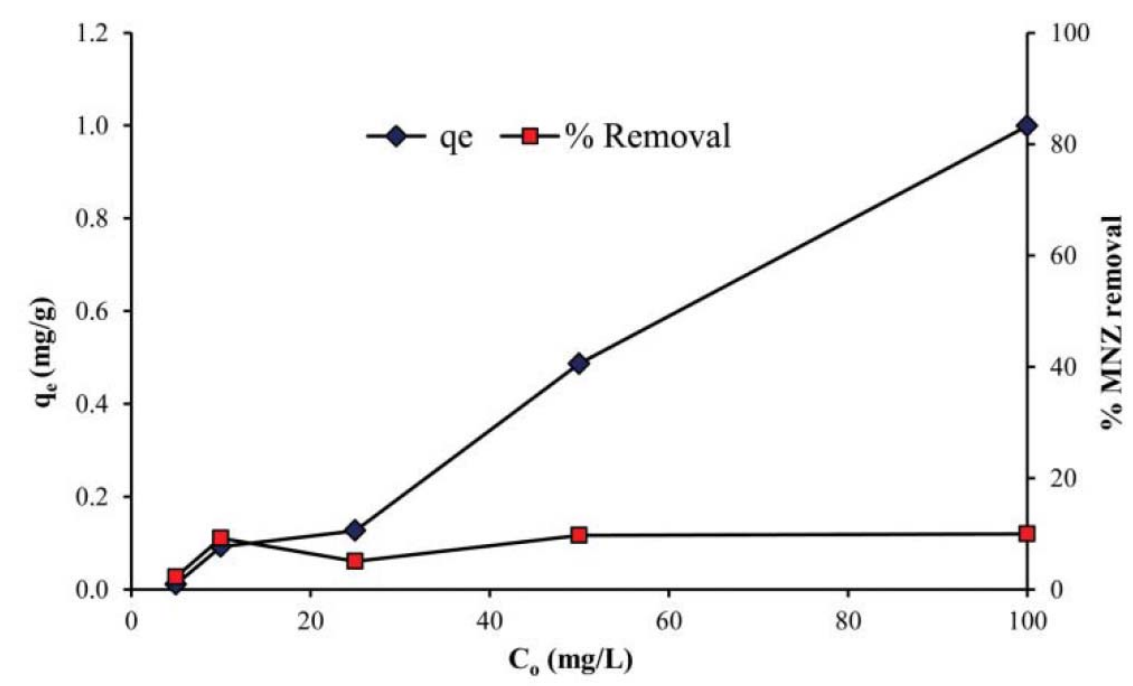

(b)

Figure 2. Effect of initial MNZ concentration on adsorption capacity and \% MNZ removal (a) PAC (b) CG.

\subsubsection{Adsorption isotherm study}

Using the experimental data of equilibrium study, the maximum MNZ adsorption capacities of PAC and CG were found using various isotherms listed in Table 2. The MNZ adsorption in PAC was fairly well fitted to all the isotherms $\left(\mathrm{R}^{2}>0.9\right)$, whereas the Freundlich isotherm was found to be more suitable to estimate the maximum MNZ adsorption capacity on CG (Supporting information, $4 \mathrm{~S}-8 \mathrm{~S}$ ). It is worth noting in Table 2 that the $\mathrm{R}^{2}$ value for the Langmuir isotherm was higher for PAC compared with other isotherms, indicating that MNZ removal occurred through monolayer adsorption. On the other hand, the value, i.e., $\mathrm{R}^{2}$, was higher for the Freundlich isotherm for CG systems. This indicates that the removal of CG was carried out by multilayer adsorption and the $\mathrm{CG}$ has a heterogeneous surface composed of different classes of adsorption sites. However, the $\frac{1}{n}$ value was found using the Freundlich isotherm for PAC (0.466) and CG (1.082), which specifies that adsorption of MNZ on PAC was more favorable compared with CG. A similar observation was found with other isotherm models as shown in Table 2. The plot of Temkin isotherm showed a better fit for the PAC system $\left(\mathrm{R}^{2} \sim 0.98\right)$ than the CG system $\left(\mathrm{R}^{2} \sim 0.81\right)$, indicating that it was due to the chemisorption process. The constant $\mathrm{B}$ obtained from the Temkin isotherm shows that heat of adsorption was higher for PAC (13.65) compared to CG (3.12). On the other hand, the Dubinin-Radushkevich isotherm constant $\mathrm{q}_{\mathrm{m}}$ for PAC and CG was found to be 55.13 and $0.40 \mathrm{mg} / \mathrm{g}$, respectively, indicating a better adsorption for PAC compared to CG for MNZ removal. Moreover, the Elovich isotherm represented the MNZ adsorption on PAC properly $\left(\mathrm{R}^{2} \sim 0.99\right)$, whereas it was very poor in the case of $\mathrm{CG}\left(\mathrm{R}^{2} \sim 0.40\right)$. Therefore, the Elovich model cannot be used to properly interpret the $\mathrm{MNZ}$ adsorption on $\mathrm{CG}$.

On the other hand, the favorability of the adsorption process was evaluated by calculating the dimensionless parameter $\left(\mathrm{R}_{\mathrm{L}}\right)$ using Eq. (9). The $\mathrm{R}_{\mathrm{L}}$ values were found to be in the range of $0.003-$ 0.233 for PAC and $0.064-0.873$ for CG when the initial MNZ concentration varied from 5 to $100 \mathrm{mg} / \mathrm{L}$. The $\mathrm{R}_{\mathrm{L}}$ values indicate that MNZ adsorption is favorable at different initial MNZ 
concentrations. In addition, the mean free energy (E) for PAC and CG was calculated using Eq. (17) as $4,082.48 \mathrm{~kJ} / \mathrm{mol}$ and $158.11 \mathrm{~kJ} / \mathrm{mol}$, respectively. The calculated values of $\mathrm{E}$ were much greater than $16 \mathrm{~kJ} / \mathrm{mol}$, indicating that the adsorption mainly occurred by chemisorption. ${ }^{[38]}$ The aforementioned observations, i.e., values of $\frac{1}{n}, \mathrm{R}_{\mathrm{L}}$ and $\mathrm{E}$, indicate that chemisorption was responsible for MNZ adsorption on both PAC and CG. Therefore, the maximum MNZ adsorption capacity of PAC was speculated to be between 25.45 and $32.78 \mathrm{mg} / \mathrm{g}$ as three isotherms predicted (based on a chemisorption approach) a similar adsorption capacity range in the PAC systems. On the other hand, the adsorption capacity of CG was found to be in the range of $0.41-0.002 \mathrm{mg} / \mathrm{g}$ (Table 2).

\subsection{Outcomes of CCD experiments}

\subsubsection{Effect of $\mathrm{pH}$, temperature and adsorbent dosage on MNZ removal}

The outcomes of CCD experiments are shown in Table 1. The response surfaces showing the effect of (i) adsorbent dosage and $\mathrm{pH}$, (ii) adsorbent dosage and temperature and (iii) $\mathrm{pH}$ and temperature on MNZ removal in the PAC system are presented in Figures $3 \mathrm{a}-\mathrm{c}$ and $4 \mathrm{a}-\mathrm{c}$, respectively. It can be observed that the increase in adsorbent dosage at any $\mathrm{pH}$ range shows an increase in MNZ removal (Figs. 3a and 4a). This can be attributed to the fact that increasing adsorbent dosage increases the surface area and number of active sites of the adsorbent. ${ }^{[41]}$ The $\mathrm{pH}$ of the solution has not shown any major effect on changing the adsorbent dosage required for MNZ removal. Rivera et al. ${ }^{[43]}$ reported a similar conclusion based on the removal of nitroimidazole by adsorption on activated carbon.

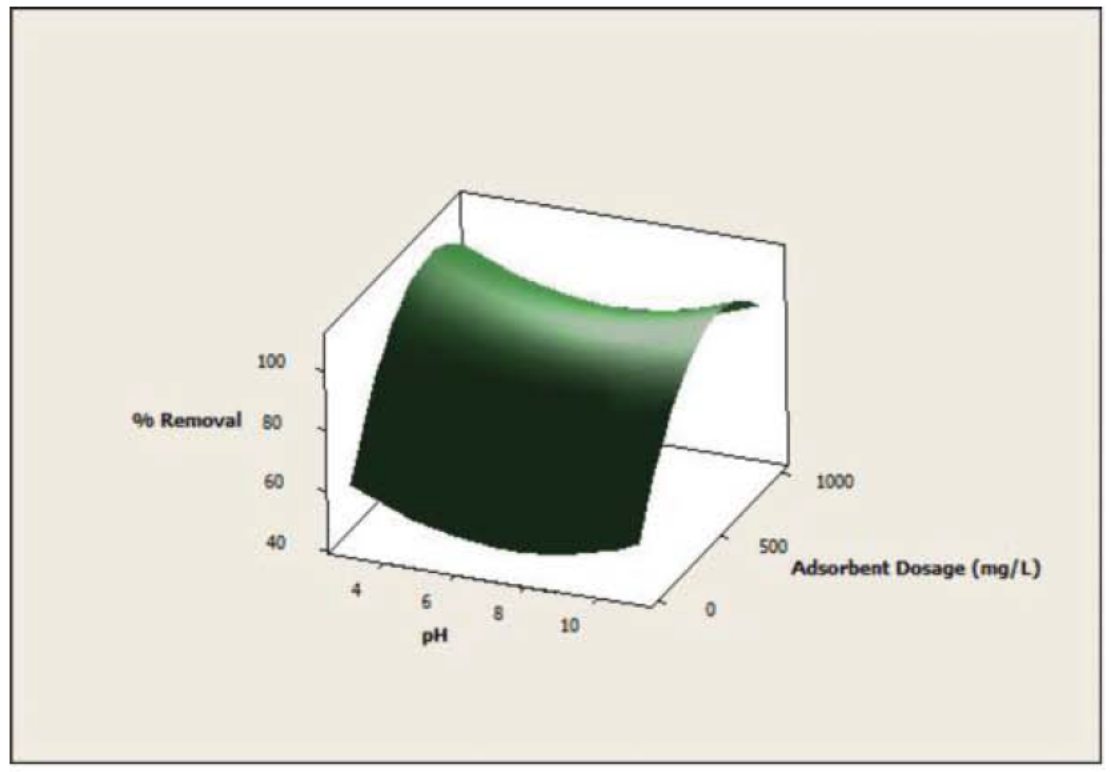

(a) 


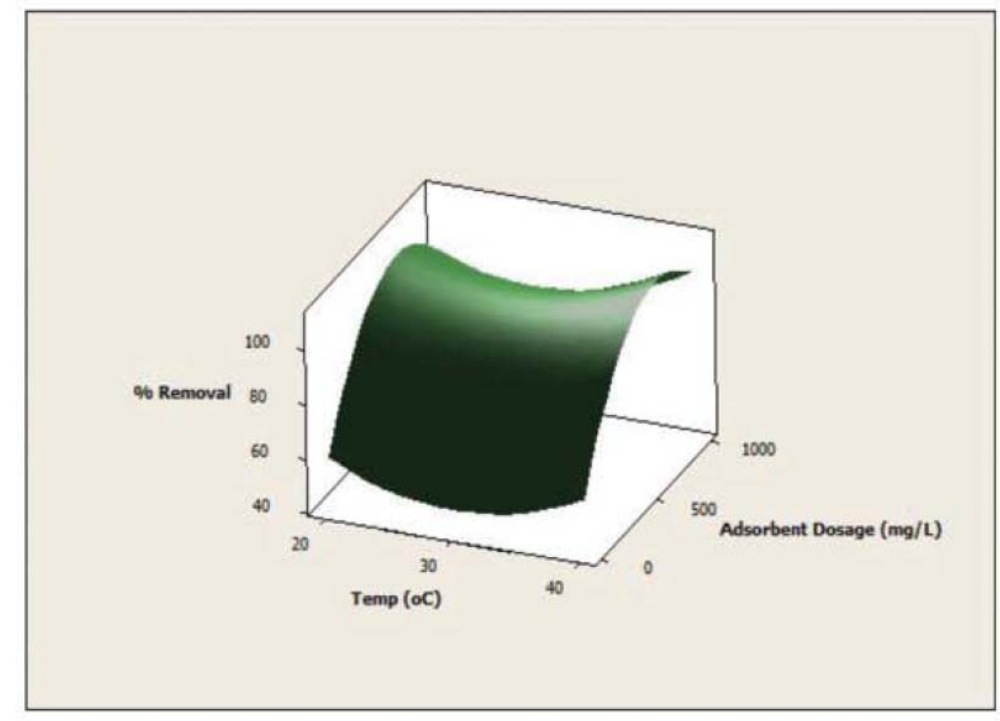

(b)

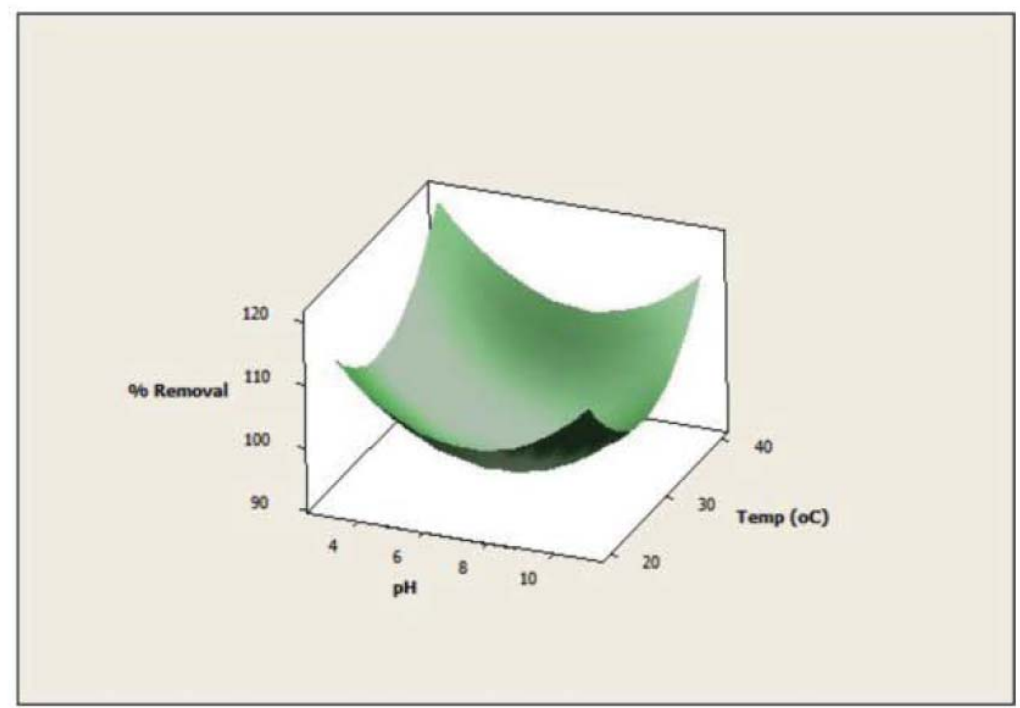

(c)

Figure 3. Effect of (a) adsorbent dosage and $\mathrm{pH}$, (b) adsorbent dosage and temperature and (c) $\mathrm{pH}$ and temperature on MNZ removal by adsorption in the PAC system.

Figures $3 \mathrm{~b}$ and $4 \mathrm{~b}$ show the response surface plots of adsorbent dosage and temperature on MNZ removal in PAC and CG systems, respectively. The maximum removal was found to be at higher temperature and at higher adsorbent dosage in both PAC and CG. The increase in MNZ removal with the increase in temperature may be due to the enlargement of pore size of adsorbent, surface activation, increase in mobility of adsorbate ions and reduced swelling effect of adsorbent. ${ }^{[37]}$ On the other hand, $\mathrm{MNZ}$ removal was found to be very less at neutral $\mathrm{pH}$ at $30^{\circ} \mathrm{C}$ compared with highly acidic and highly alkaline $\mathrm{pH}$ conditions (Fig. 3c). A similar trend was observed in the CG system, i.e., the percentage $\mathrm{MNZ}$ removed was found to be higher in acidic $\mathrm{pH}$ at a higher temperature (Fig. 4c). 


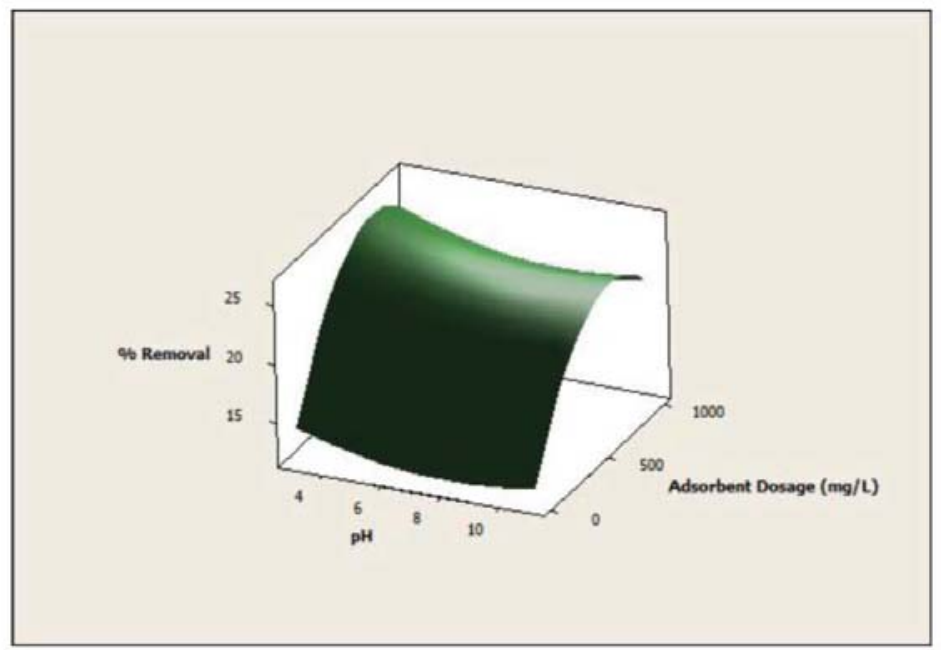

(a)

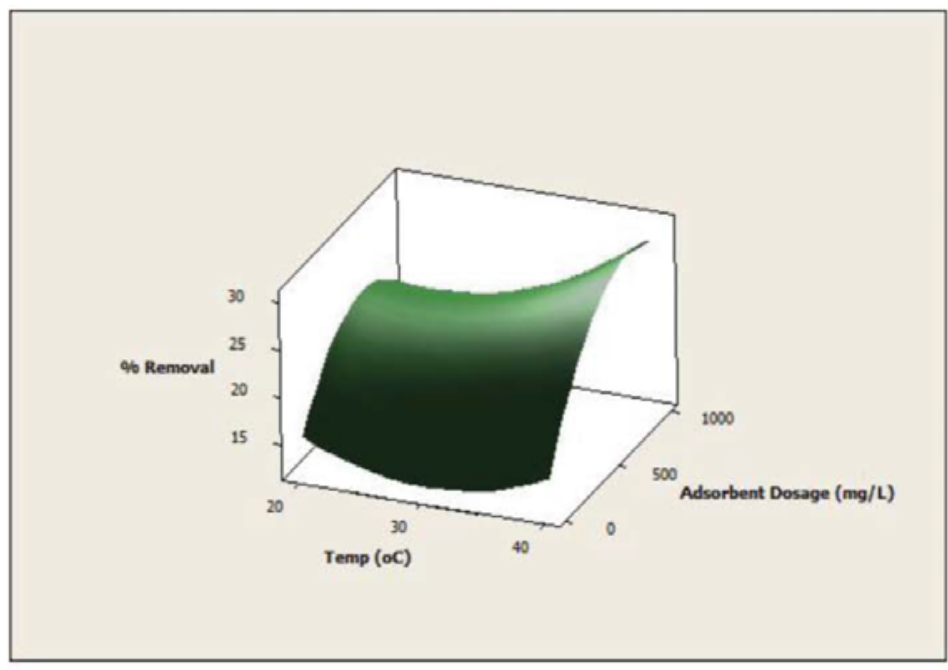

(b)

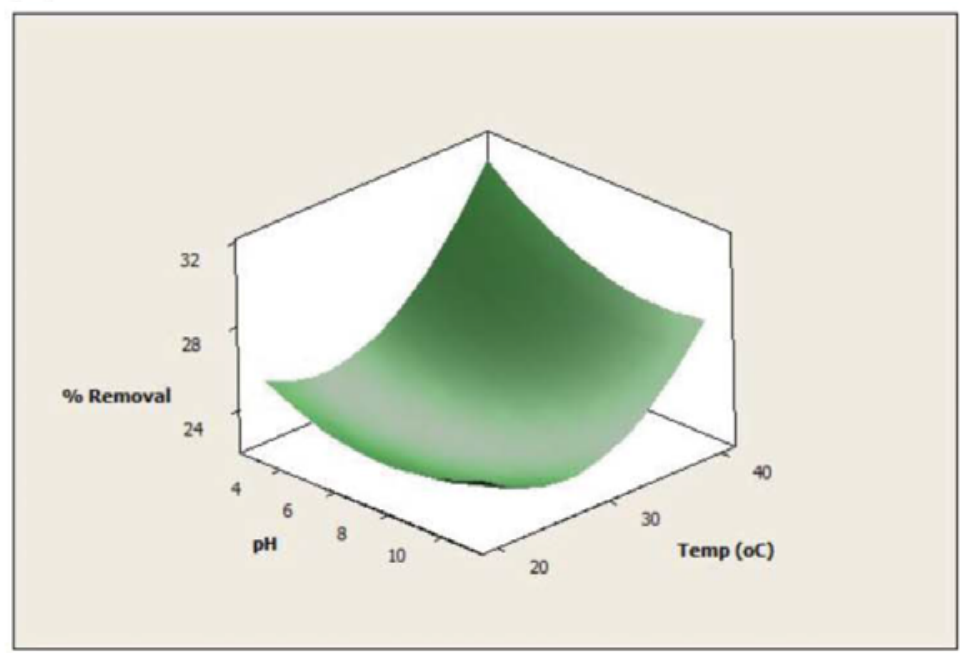

(c)

Figure 4. Effect of (a) adsorbent dosage and $\mathrm{pH}$, (b) adsorbent dosage and temperature and (c) $\mathrm{pH}$ and temperature on MNZ removal by adsorption in the CG system. 
The empirical relationship between the three independent variables and response can be represented by a generic equation as given in Eq. (24), where $\mathrm{Y}$ is a response and $\mathrm{x}_{\mathrm{ij}}$ represents independent variables. A second-order quadratic model was obtained using the CCD data as shown in Eqs. (24) and (25), which gives the empirical relationship between the independent variables ( $\mathrm{x}_{1}$, $\mathrm{x}_{2}$ and $\mathrm{x}_{3}$ ) and the MNZ removal (dependent variable, i.e., Y) for PAC and CG, respectively. These equations can be used to calculate a set of combinations of $\mathrm{x}_{1}, \mathrm{x}_{2}$ and $\mathrm{x}_{3}$ for a predetermined $\mathrm{Y}$ value, which will be useful in real-time operations.

$$
\begin{aligned}
Y= & b_{o}+\sum b_{i} x_{i}+\sum b_{i i} x_{i}^{2}+\sum b_{i j} x_{i} x_{j} \\
Y_{P A C}= & 183.8300-9.3976 x_{1}-6.8853 x_{2}+0.1369 x_{3} \\
& +0.6654 x_{1}^{2}+0.1169 x_{2}^{2}-0.0001 x_{3}^{2}-0.0149 x_{1} x_{2} \\
& +0.0001 x_{1} x_{3}+0.0003 x_{2} x_{3} \\
Y_{C G}= & 40.9737-0.8443 x_{1}-1.6914 x_{2}+0.0217 x_{3} \\
+ & 0.0865 x_{1}^{2}+0.0300 x_{2}^{2}-0.00003 x_{3}^{2} \\
- & 0.0177 x_{1} x_{2}+0.0001 x_{1} x_{3}+0.0005 x_{2} x_{3}
\end{aligned}
$$

where $b_{o}, b_{i}, b_{i i}$ and $b_{i j}$ are the constants obtained from the model, YPAC and YCG represent the MNZ removal by PAC and CG, respectively.

\subsubsection{Variation of Gibbs free energy with adsorbent dosage, temperature and $\mathrm{pH}$}

Figure 5a-f shows the surface plots of $\Delta \mathrm{G}^{\circ}$ with respect to interaction between adsorbent dosage, $\mathrm{pH}$ and temperature for PAC and $\mathrm{CG}$, respectively. In Figure $5 \mathrm{a}, \Delta \mathrm{G}^{0}$ was the lowest (more negative) at $\mathrm{pH} 4$ and at an adsorbent dosage of $1,000 \mathrm{mg} / \mathrm{L}$, which indicate that the $\mathrm{MNZ}$ adsorption is highly spantaneous in the PAC system. On the other hand, $\Delta \mathrm{G}^{0}$ decreased as adsorbent dosage decreased and $\mathrm{pH}$ showed no significant effect on $\Delta \mathrm{G}^{0}$ in the CG system (Fig. $5 \mathrm{~b}$ ). In Figure $5 \mathrm{c}, \Delta \mathrm{G}^{0}$ was more negative at $40^{\circ} \mathrm{C}$ and adsorbent dosage of $1,000 \mathrm{mg} / \mathrm{L}$ in the PAC system, whereas $\Delta \mathrm{G}^{0}$ decreased as adsorbent dosage decreased and temperature showed much less significant effect on DGo value in the CG system (Fig. 5d). For PAC, $\Delta \mathrm{G}^{0}$ was more negative at $\mathrm{pH} 4$ and at $40^{\circ} \mathrm{C}$ (Fig. 5e). On the other hand, the lower value of $\Delta \mathrm{G}^{0}$ can be noticed at $\mathrm{pH} 4$ and at $40^{\circ} \mathrm{C}$ for $\mathrm{CG}$ (Fig. 5f). Overall, higher adsorbent dosage at acidic $\mathrm{pH}$ and at higher temperature makes the adsorption process more feasible and spontaneous for PAC.

\subsubsection{Optimization of operating conditions}

The suitable operational conditions/combinations, i.e., adsorbent dosage, temperature and $\mathrm{pH}$, for almost complete MNZ removal by PAC were analyzed using the response optimizer function in Minitab. The different operationally suitable combinations of adsorbent dosage, temperature and $\mathrm{pH}$ for complete MNZ removal using PAC as adsorbent are shown in Table 3. On the other hand, only $86.7 \%$ of $\mathrm{MNZ}$ removal was observed in the kinetic study when the experiment was conducted at $10 \mathrm{mg} / \mathrm{L} \mathrm{MNZ,} \mathrm{pH} 7$ and at $25^{\circ} \mathrm{C}$ with $1,000 \mathrm{mg} / \mathrm{L}$ PAC dosage. The increase in system's temperature from $25^{\circ} \mathrm{C}$ to $36^{\circ} \mathrm{C}$ and $40^{\circ} \mathrm{C}$ could completely remove $\mathrm{MNZ}$ at much lower dosages. 
Nearly $62 \%$ less adsorbent dosage is required and moreover complete MNZ removal could be achieved at the elevated temperature.

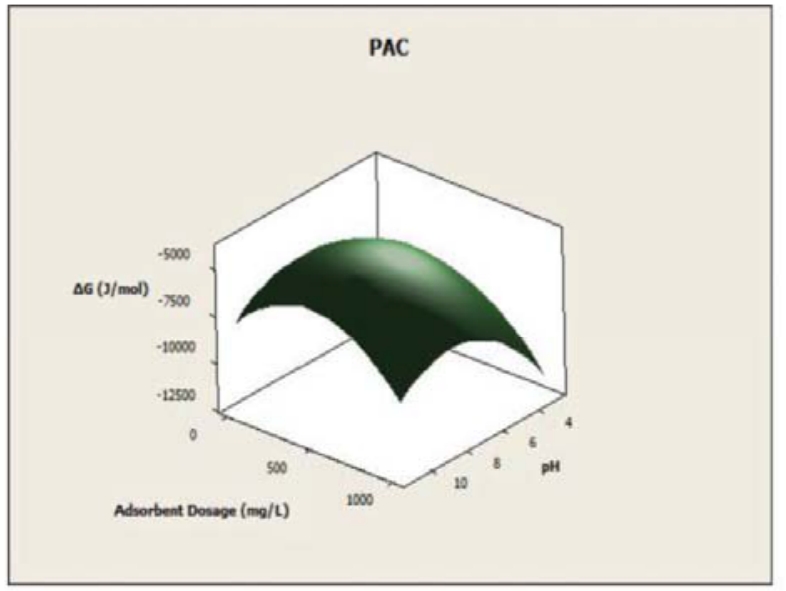

(a)

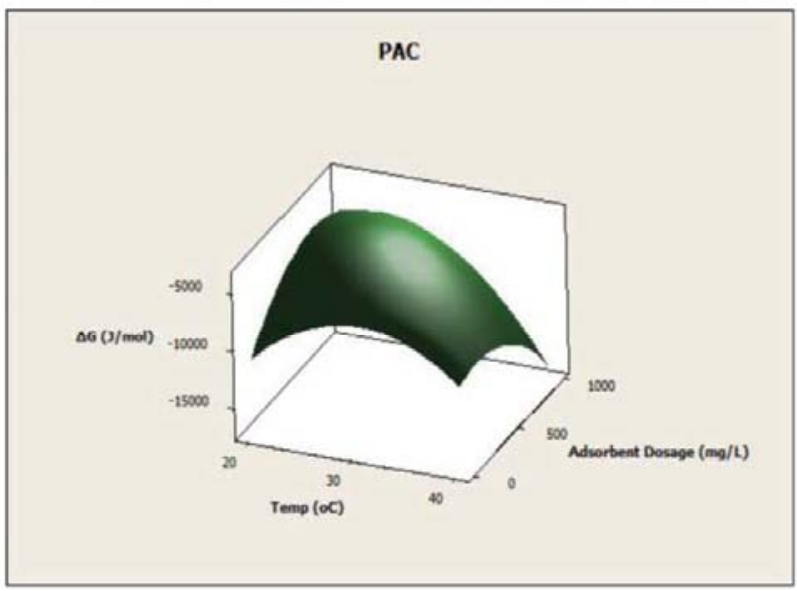

(c)

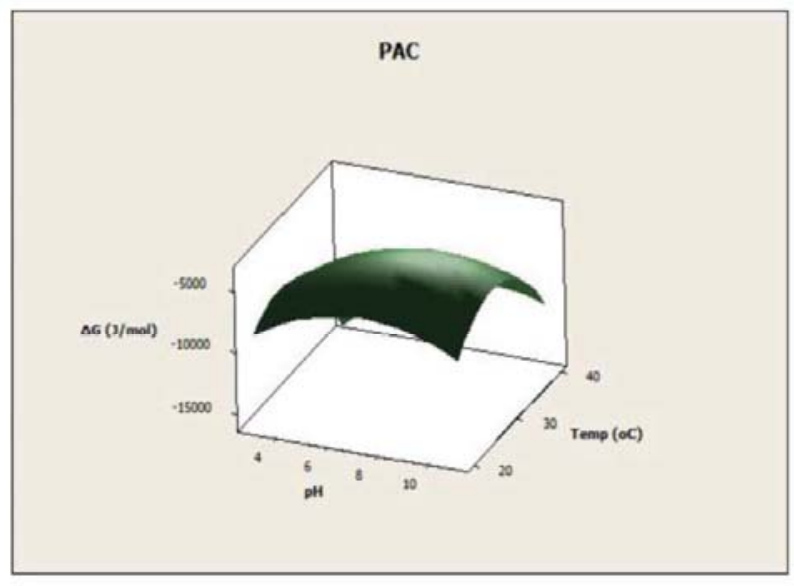

(e)

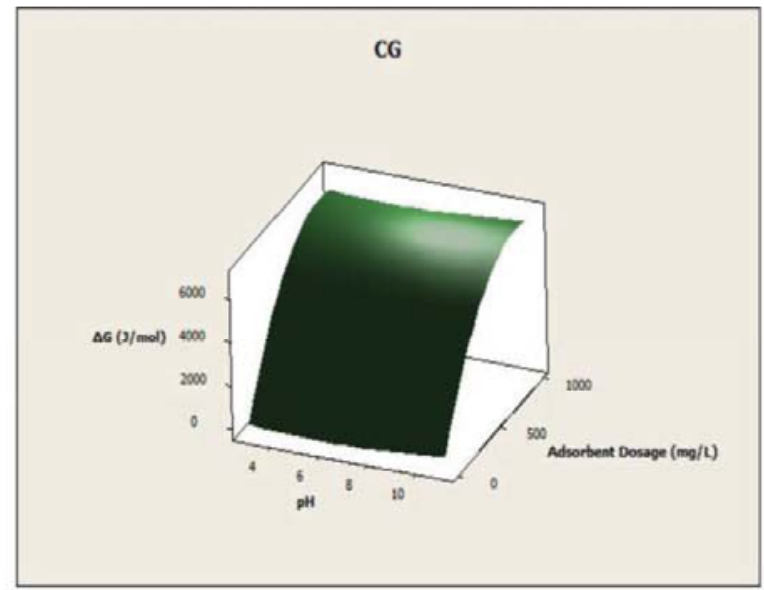

(b)

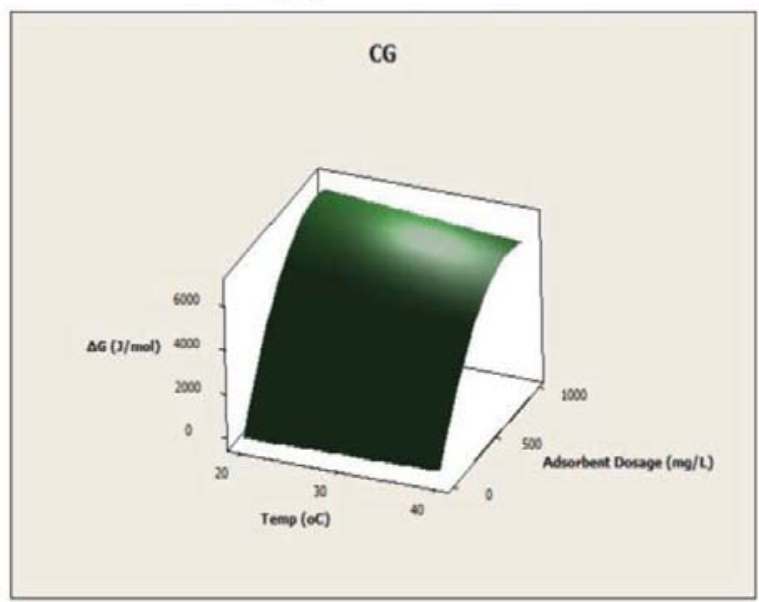

(d)

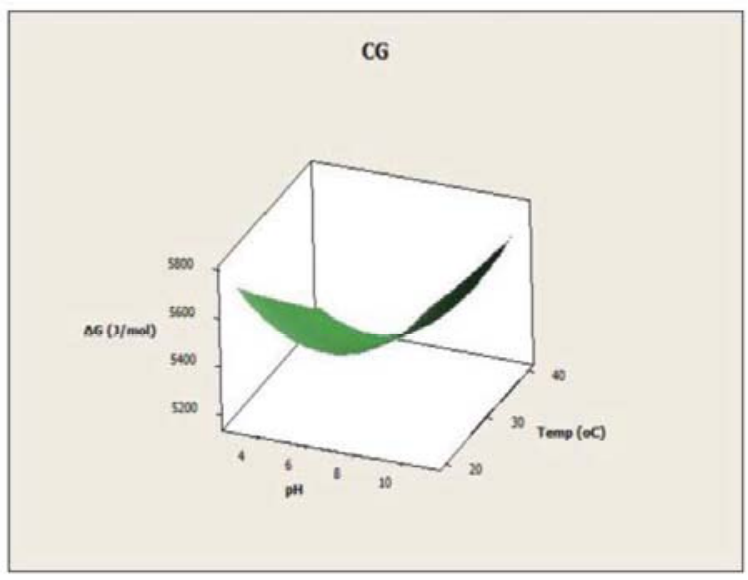

(f)

Figure 5. $(\mathrm{a}-\mathrm{f})$ Three-dimensional surface plot of variation of $\Delta \mathrm{G}^{0}$ with respect to interaction between adsorbent dosage $\mathrm{pH}$ and temperature for PAC and CG. 
Table 3. Operating conditions for complete MNZ removal in the PAC adsorption system.

\begin{tabular}{lcccc}
\hline $\begin{array}{l}\text { MNZ concentration } \\
(\mathrm{mg} / \mathrm{L})\end{array}$ & $\mathrm{pH}$ & $\begin{array}{c}\text { Temperature } \\
\left({ }^{\circ} \mathrm{C}\right)\end{array}$ & $\begin{array}{c}\text { Adsorbent dosage } \\
(\mathrm{mg} / \mathrm{L})\end{array}$ & $\begin{array}{c}\text { Removal } \\
(\%)\end{array}$ \\
\hline 10 & 7 & 36 & 800 & 100 \\
& & 39.5 & 400 & \\
& & 40 & 384 & \\
& & 25 & 1,000 & 86.7 \\
\hline
\end{tabular}

\subsection{Correlation of MNZ adsorption and thermodynamic parameters}

The correlation between temperature and MNZ removal was analyzed by estimating the thermodynamic parameters using Eqs. (20)-(23). The calculation of thermodynamic parameters is possible based on the constants from Langmuir, Frumkin, Flory-Huggins, Liu isotherms and also from thermodynamic equilibrium constant as shown in Eq. (23). However, $\mathrm{k}_{\mathrm{c}}$ was calculated based on Eq. (23) and the observations of thermodynamic parameters with respect to change in temperature were in good agreement with the earlier observations. ${ }^{[44]}$ However, the thermodynamic parameters can also be calculated based on the Langmuir constant for organic compounds with weak charges like MNZ as suggested by Liu. ${ }^{[45]}$

The calculated values of $\mathrm{k}_{\mathrm{c}}, \Delta \mathrm{G}^{0}, \Delta \mathrm{H}^{0}$ and $\Delta \mathrm{S}^{0}$ based on thermodynamic equilibrium constants considering weak charges of MNZ are shown in Table 4. The values of $\Delta \mathrm{H}^{0}$ and $\Delta \mathrm{S}^{0}$ were found to be positive for both $\mathrm{PAC}$ and $\mathrm{CG}$, whereas the $\Delta \mathrm{G}^{0}$ value was negative for PAC and positive for CG. The negative $\Delta \mathrm{G}^{0}$ value for PAC indicates that the adsorption process is thermodynamically feasible and spontaneous in nature, whereas the positive $\Delta \mathrm{G}^{0}$ value for $C G$ indicates the nonspontaneous nature of MNZ adsorption. For PAC and CG, the value of $\Delta \mathrm{G}^{0}$ decreases as temperature increases, suggesting that higher temperature favors the adsorption process. However, the positive $\Delta \mathrm{H}^{0}$ value for both PAC and CG indicates that the adsorption process is endothermic in nature. The adsorption process in the solid-liquid system is a combination of two processes, i.e., desorption of previously adsorbed water molecules from adsorbent surface and adsorption of adsorbate species. For MNZ adsorption on the adsorbent surface, MNZ ions have to replace more than one water molecule, which would have resulted in the adsorption process being endothermic. ${ }^{[46]}$ An endothermic process obtains its energy in the form of heat from surrounding molecules/environment, which could be unequivocally attributed to the chemisorption process. ${ }^{[47]}$ At the same time, the positive $\Delta \mathrm{S}^{0}$ value for PAC and CG indicates increased randomness at the solid-solution interface during the fixation of MNZ ions on active sites of adsorbents. ${ }^{[48]}$ Thus, an increase in MNZ adsorption was observed at higher temperatures. The whole outcome of adsorption experiments reveals that MNZ adsorption by $\mathrm{CG}$ (with a graphene content of $2 \% \mathrm{w} / \mathrm{w}$ ) is insignificant compared to the removal by PAC. However, MNZ removal in the CG system could be improved by increasing the graphene content of concrete. However, the cost required and uniformity in adsorbent preparation would be the likely challenges, which needs a detailed investigation. 
Table 4. Thermodynamic constants of PAC and CG for MNZ removal.

\begin{tabular}{lcccccc}
\hline \multirow{2}{*}{ Adsorbent } & Temperature (K) & $k_{c}$ & $\Delta G^{o}(\mathrm{~J} / \mathrm{mol})$ & $\begin{array}{c}\Delta H^{o} \\
(\mathrm{~mol})\end{array}$ & $\begin{array}{c}\Delta S^{o} \\
(\mathrm{~J} / \mathrm{mol} / \mathrm{K})\end{array}$ & $\mathrm{R}^{2}$ \\
\hline \multirow{2}{*}{ PAC } & 293 & 4.11 & $-3,441.6$ & 111548 & 389.5 & 0.843 \\
& 303 & 6.27 & $-6,465.3$ & & & \\
CG & 313 & 78.11 & $-11,341.2$ & & & \\
& 293 & 0.11 & $5,376.92$ & 11014 & 19.17 & 0.962 \\
& 303 & 0.12 & $5,341.2$ & & & \\
\hline
\end{tabular}

\subsection{Desorption study}

The desorption study helps to explain the mechanism of adsorption process. ${ }^{[48-50]}$ An adsorbate's weak association with the adsorbent could be removed by water (i.e., universal solvent), which is an indication of weak bonds during the adsorption process. On the other hand, the removal that could be possible by strong base/strong acid or by organic acids is an indication of adsorption by the exchange of ions or chemisorption process, respectively. Figure 6 shows the percentage of MNZ desorbed from the surface of PAC and CG after $24 \mathrm{~h}$. A maximum of 3.5\% and $1.7 \% \mathrm{MNZ}$ desorption was observed in the PAC and CG systems, respectively. The very low MNZ desorption by distilled water from PAC and CG systems indicates that some complexes may have formed between active sites of adsorbents and MNZ species. However, strong acidic solvents $\left(\mathrm{HCl}, \mathrm{H}_{2} \mathrm{SO}_{4}\right.$ and $\left.\mathrm{HNO}_{3}\right)$, strong basic solvents $(\mathrm{NaOH})$ and organic acids $\left(\mathrm{CH}_{3} \mathrm{COOH}\right)$ may promote the $\mathrm{MNZ}$ recovery and the regeneration of adsorbents.

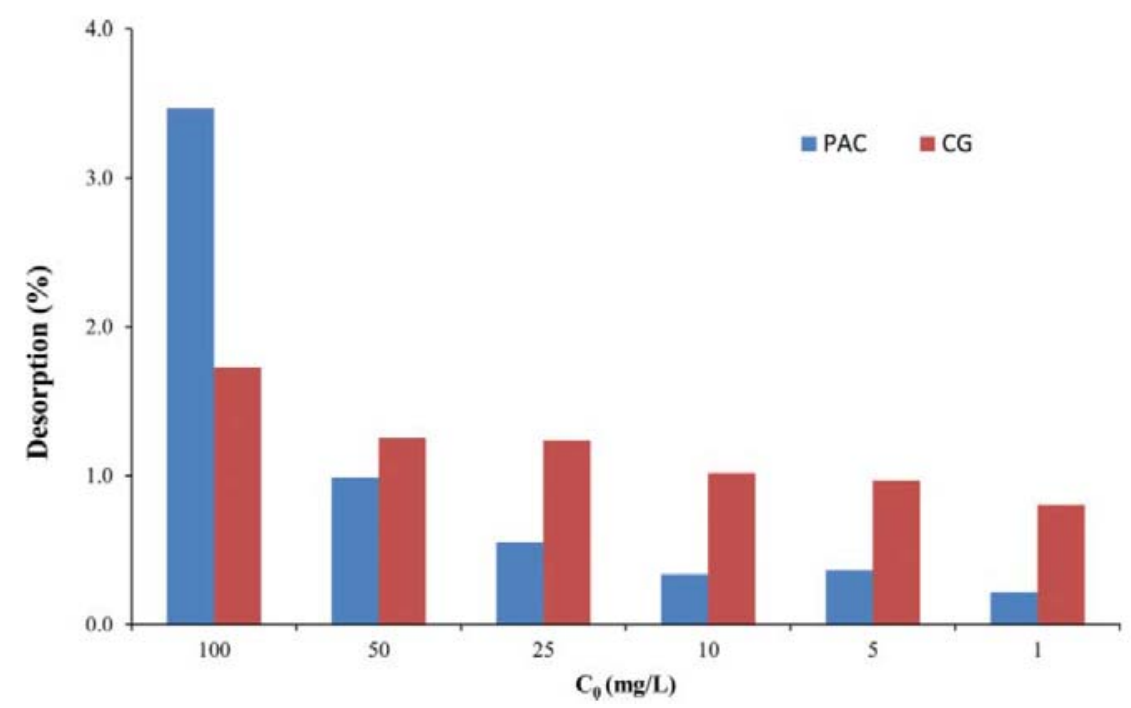

Figure 6. MNZ desorption from PAC and CG adsorption systems. 


\section{Conclusions}

Batch-mode MNZ adsorption experiments were carried out using PAC and CG. The MNZ adsorption capacity of PAC was 45 times higher compared to CG. Adsorption of MNZ on both $\mathrm{PAC}$ and $\mathrm{CG}$ followed the pseudo-second-order kinetic model. The increase in the system's temperature $\left(20-40^{\circ} \mathrm{C}\right)$ ensured complete removal of $\mathrm{MNZ}$ at a much lower dosage of PAC. Thermodynamic parameters indicated that MNZ adsorption on PAC was spontaneous and endothermic. On the other hand, the MNZ removal was non-spontaneous and endothermic on CG. The outcome of adsorption experiments pointed out that MNZ removal by CG was insignificant compared to PAC. The quantity of MNZ desorbed from PAC and CG was very low with distilled water, which indicated the formation of complexes during chemisorption. The application of solvents and/or other acidic reagents could be useful for MNZ recovery. As a whole, PAC and CG with more graphene content could be useful in treating water and wastewater containing MNZ and other similar compounds.

\section{Acknowledgements}

The authors are grateful to the research collaboration between IIT Madras and University of Technology Sydney.

\section{Funding}

The authors acknowledge the financial support provided by the Centre for Industrial Consultancy and Sponsored Research (ICSR), IIT Madras, which made this research study (Grant No: CIE/1415/832/NFIG/SMAT and CIE/14-15/650/NFSC/SMAT) possible.

\section{Supplementary Materials}

Supplementary data related to this article can be found at http://orcid.org/0000-0002-4124-4605.

\section{References}

[1] Liu, J.L.; Wong, M.-H. Pharmaceuticals and personal care products (PPCPs): A review on environmental contamination in China. Environ. Int. 2013, 59, 208-224.

[2] Lanzky, P.F.; Haning-Sorensen, B. The toxic effect of the antibiotic metronidazole on aquatic organisms. Chemosphere 1997, 35, 2553-2561.

[3] Manamsa, K.; Crane, E.; Stuart, M.; Talbot, J.; Lapworth, D.; Hart, A. A national-scale assessment of micro-organic contaminants in groundwater of England and Wales. Sci. Total Environ. 2016, $568,712-726$.

[4] Phillips, P.J.; Schubert, C.; Argue, D.; Fisher, I.; Furlong, E.T., Foreman, W.; Gray, J.; Chalmers, A. Concentrations of hormones, pharmaceuticals and other micropollutants in groundwater affected by septic systems in New England and New York. Sci. Total Environ. 2015, 512-513, $43-54$.

[5] Vulliet, E.; Cren-Oliv_e, C. Screening of pharmaceuticals and hormones at the regional scale, in surface and groundwaters intended to human consumption. Environ. Pollut. 2011, 159, 2929-2934.

[6] Cabeza, Y.; Candela, L.; Ronen, D.; Teijon, G. Monitoring the occurrence of emerging contaminants in treated wastewater and groundwater between 2008 and 2010. The Baix Llobregat (Barcelona, Spain). J. Hazard. Mater. 2012, 239-240, 32-39. 
[7] K'oreje, K.O.; Vergeynst, L.; Ombaka, D.; De Wispelaere, P.; Okoth, M.; Van Langenhove, H.; Demeestere, K. Occurrence patterns of pharmaceutical residues in wastewater, surface water and groundwater of Nairobi and Kisumu city, Kenya. Chemosphere 2016, 149, 238-244.

[8] Ammar, H.B.; Brahim, M.B.; Abdelh_edi, R.; Samet, Y. Green electrochemical process for metronidazole degradation at BDD anode in aqueous solutions via direct and indirect oxidation. Sep. Purif. Technol. 2016, 157, 9-16.

[9] Fang, Z.; Chen, J.; Qiu, X.; Qiu, X.; Cheng, W.; Zhu, L. Effective removal of antibiotic metronidazole from water by nanoscale zerovalent iron particles. Desalination. 2011, 268, 60-67.

[10] Rosal, R.; Rodríguez, A.; Perdigón-Melón, J.A.; Petre, A.; García-Calvo, E.; Gómez, M.J.; Aguera, A.; Fernandez-Alba, A.R. Occurrence of emerging pollutants in urban wastewater and their removal through biological treatment followed by ozonation. Water Res. 2010, 44, 578-588.

[11] Kümmerer, K.; Al-Ahmad, A.; Mersch-Sundermann, V. Biodegradability of some antibiotics, elimination of the genotoxicity and affection of wastewater bacteria in a simple test. Chemosphere 2000, 40, 701-710.

[12] Chianeh, F.N.; Parsa, J.B. Electrochemical degradation of metronidazole from aqueous solutions using stainless steel anode coated with $\mathrm{SnO}_{2}$ nanoparticles: Experimental design. Rev. Mex. Urol. 2016, 76, 424-432.

[13] Dong, S.; Sun, J.; Li, Y.; Yu, C.; Li, Y.; Sun, J. ZnSnO 3 hollow nanospheres/reduced graphene oxide nanocomposites as high-performance photocatalysts for degradation of metronidazole. Appl. Catal. B Environ. 2014, 144, 386-393.

[14] Saidi, I.; Soutrel, I.; Fourcade, F.; Amrane, A.; Bellakhal, N.; Geneste, F. Electrocatalytic reduction of metronidazole using titanocene/Nafion ${ }^{\circledR}$-modified graphite felt electrode. Electrochim. Acta. 2016, 191, 821-831.

[15] Yang, J.; Zhu, M.; Wang, X.; Alvarez, P.J.J.; Liu, K. Poly(vinylidene fluoride) membrane supported nano zero-valent iron for metronidazole removal: Influences of calcium and bicarbonate ions. J. Taiwan Inst. Chem. Eng. 2015, 49, 113-118.

[16] Ammar, H.B.; Brahim, M.B.; Abdelhédi, R.; Samet, Y. Enhanced degradation of metronidazole by sunlight via photo-Fenton process under gradual addition of hydrogen peroxide. J. Mol. Catal. A Chem. 2016, 420, 222-227.

[17] Saidi, I.; Soutrel, I.; Floner, D.; Fourcade, F.; Bellakhal, N.; Amrane, A.; Geneste, F. Indirect electroreduction as pretreatment to enhance biodegradability of metronidazole. J. Hazard. Mater. 2014, 278, 172-179.

[18] Foo, K.Y.; Hameed, B.H. Insights into the modeling of adsorption isotherm systems. Chem. Eng. J. 2010, 156, 2-10.

[19] Rangabhashiyam, S.; Nandagopal, M.S.G.; Nakkeeran, E.; Selvaraju, N. Adsorption of hexavalent chromium from synthetic and electroplating effluent on chemically modified Swietenia mahagoni shell in a packed bed column, Environ. Monit. Assess. 2016, 188, 1-13.

[20] Nitivattananon, V.; Borongan, G. Construction and demolition waste management: Current practices in Asia. Proceedings of the International Conference on Sustainable Solid Waste Management, 5-7 Sept, Chennai, India, 2007, 97-104.

[21] Wang, X.; Chen, J.; Kong, Y.; Shi, X. Sequestration of phosphorus from wastewater by cementbased or alternative cementitious materials. Water Res. 2014, 62, 86-96. 
[22] Jo, M.; Soto, L.; Arocho, M.; St John, J.; Hwang, S. Optimum mix design of fly ash geopolymer paste and its use in pervious concrete for removal of fecal coliforms and phosphorus in water. Constr. Build. Mater. 2015, 93, 1097-1104.

[23] Wang, Z.; Chen, Z.; Chang, J.; Shen, J.; Kang, J.; Chen, Q. Fabrication of a low-cost cementitious catalytic membrane for $\mathrm{p}$-chloronitrobenzene degradation using a hybrid ozonation-membrane filtration system. Chem. Eng. J. 2015, 262, 904-912.

[24] De-Andrade, F.V.; De-Lima, G.M.; Augusti, R.; Da-Silva, J.C.C.; Coelho, M.G.; Paniago, R.; Machado, I.R. A novel TiO2/autoclaved cellular concrete composite: From a precast building material to a new floating photocatalyst for degradation of organic water contaminants. J. Water. Process. Eng. 2015, 7, 27-35.

[25] Ok, Y.S.; Yang, J.E.; Zhang, Y.S.; Kim, S.J.; Chung, D.Y. Heavy metal adsorption by a formulated zeolite-portland cement mixture. J. Hazard. Mater. 2007, 147, 91-96.

[26] Karkar, S.; Debnath, S.; De, P.; Parashar, K.; Pillay, K.; Sashikumar, P.; Ghosh, U.C. Preparation, characterization and evaluation of fluoride adsorption efficiency from water of ironaluminium oxide-graphene oxide composite material. Chem. Eng. J. 2016, 306, 269-279.

[27] Nam, S.W.; Jung, C.; Li, H.; Yu, M.; Flora, J.R.V.; Boateng, L.K.; Her, N.; Zoh, K.D.; Yoon, Y. Adsorption characteristics of diclofenac and sulfamethoxazole to graphene oxide in aqueous solution. Chemosphere 2015, 136, 20-26.

[28] Qi, Y.; Yang, M.; Xu, W.; He, S.; Men, Y. Natural polysaccharides-modified graphene oxide for adsorption of organic dyes from aqueous solutions. J. Colloid. Interface Sci. 2017, 486, 84-96.

[29] Tan, P.; Hu, Y.; Bi, Q. Competitive adsorption of $\mathrm{Cu}^{2+}, \mathrm{Cd}^{2+}$ and $\mathrm{Ni}^{2+}$ from an aqueous solution on graphene oxide membranes. Colloids Surf A Physicochem. Eng. Asp. 2016, 509, 56-64.

[30] Rodrigues, A.E.; Silva, C.M. What's wrong with Lagergren pseudo first order model for adsorption kinetics? Chem. Eng. J. 2016, 306, 1138-1142.

[31] Ho, Y.S.; McKay, G. The kinetics of sorption of divalent metal ions onto Sphagnum moss peat. Water Res. 2000, 34, 735-742.

[32] Ho, Y.S.; McKay, G. Pseudo second order model for sorption processes. Process Biochem. 1999, 34, 451-465.

[33] Rangabhashiyam, S.; Anu, N.; Giri-Nandagopal, M.S.; Selvaraju, N. Relevance of isotherm models in biosorption of pollutants by agricultural byproducts. J. Environ. Chem. Eng. 2014, 2, $398-414$.

[34] Langmuir, I. The Constitution and fundamental properties of solids and liquids. Part I. Solids. J. Am. Chem. Soc. 1916, 38, 2221-2295.

[35] Freundlich, H.; Heller, W. The Adsorption of cis- and trans-Azobenzene. J. Am. Chem. Soc. 1939, $61,2228-2230$.

[36] Temkin, M.J.; Phyzev, V. Recent modifications to Langmuir isotherms. Acta Physico-Chimica USSR. 1940, 12, 217-222.

[37] Rangabhashiyam, S.; Selvaraju, N. Evaluation of the biosorption potential of a novel Caryota urens inflorescence waste biomass for the removal of hexavalent chromium from aqueous solutions. J. Taiwan Inst. Chem. Eng. 2015, 47, 59-70.

[38] Ghasemi, M.; Naushad, M.; Ghasemi, N.; Khosravi-fard, Y. Adsorption of Pb(II) from aqueous solution using new adsorbents prepared from agricultural waste: adsorption isotherm and kinetic studies. J. Ind. Eng. Chem. 2014, 20, 2193-2199. 
[39] Hamdaoui, O.; Naffrechoux, E. Modeling of adsorption isotherms of phenol and chlorophenols onto granular activated carbon. Part I. Two-parameter models and equations allowing determination of thermodynamic parameters. J. Hazard. Mater. 2007, 147, 381-394.

[40] Rangabhashiyam, S.; Nakkeeran, E., Anu, N., Selvaraju, N. Biosorption potential of a novel powder, prepared from Ficus auriculata leaves, for sequestration of hexavalent chromium from aqueous solutions. Res. Chem. Intermed. 2015, 41, 8405-8424.

[41] Srivastava, V.C.; Swamy, M.M.; Mall, I.D.; Prasad, B.; Mishra, I.M. Adsorptive removal of phenol by bagasse fly ash and activated carbon: equilibrium, kinetics and thermodynamics. Colloids Surf. A Physicochem. Eng. Asp. 2006, 272, 89-104.

[42] Singh, R.K.; Kumar, S.; Kumar, S.; Kumar, A. Development of parthenium based activated carbon and its utilization for adsorptive removal of p-cresol from aqueous solution. J. Hazard. Mater. 2008, $155,523-535$.

[43] Rivera-Utrilla, J.; Prados-Joya, G.; Sánchez-Polo, M.; Ferro-García, M.A.; Bautista-Toledo, I. Removal of nitroimidazole antibiotics from aqueous solution by adsorption/bioadsorption on activated carbon. J. Hazard. Mater. 2009, 170, 298-305.

[44] Liu, Y.; $\mathrm{Xu}, \mathrm{H}$. Equilibrium, thermodynamics and mechanisms of $\mathrm{Ni}^{2+}$ biosorption by aerobic granules. Biochem. Eng. J. 2007, 35, 174-182.

[45] Liu, Y. Is the free energy change of adsorption correctly calculated? J. Chem. Eng. Data 2009, 54, 1981-1985.

[46] Rawat, V.; Rai, P.; Gautam, R.K.; Chattopadhyaya, M.C. Kinetic and equilibrium isotherm studies for the adsorptive removal of brilliant green dye from aqueous solution by Oplismenus frumentaceus husk. J. Indian Chem. Soc. 2013, 90, 577-583.

[47] Tran, H.N.; You, S.J.; Chao, H.P. Thermodynamic parameters of cadmium adsorption onto orange peel calculated from various methods: A comparison study. J. Environ. Chem. Eng. 2016, 4, 26712682.

[48] Lataye, D.H.; Mishra, I.M.; Mall, I.D. Removal of 4-Picoline from aqueous solution by adsorption onto bagasse fly ash and rice husk ash: Equilibrium, thermodynamic, and desorption study. J. Environ. Eng. 2011, 137, 1048-1057.

[49] Kumar, M.; Philip, L. Adsorption and desorption characteristics of hydrophobic pesticide endosulfan in four Indian soils. Chemosphere 2006, 62, 1064-1077.

[50] Rangabhashiyam, S.; Selvaraju, N. Efficacy of unmodified and chemically modified Swietenia mahagoni shells for the removal of hexavalent chromium from simulated wastewater. J. Mol. Liq. 2015, 209, 487-497.

[51] Mall, I.D.; Srivastava, V.C.; Kumar, G.V.A.; Mishra, I.M. Characterization and utilization of mesoporous fertilizer plant waste carbon for adsorptive removal of dyes from aqueous solution. Colloids Surf. A Physicochem. Eng. Asp. 2006, 278, 175-187. 